\title{
Reflectance Confocal Microscopy Identification of Subclinical Basal Cell Carcinoma after Vismodegib Treatment: Report of a Case
}

\author{
Alessia Villani (D) · Gabriella Fabbrocini · Claudia Costa • \\ Massimiliano Scalvenzi
}

Received: March 7, 2021 / Accepted: April 9, 2021 / Published online: April 15, 2021

(c) The Author(s) 2021

\begin{abstract}
Although surgery represents the treatment of choice for the majority of basal cell carcinomas, different therapies are required to treat the advanced ones. Vismodegib and sonidegib are the two oral Smoothened (Smo) inhibitors approved for the treatment of advanced basal cell carcinoma. Clinical detection of subclinical basal cell carcinoma during and after vismodegib treatment could be difficult, requiring the use of dermoscopy and reflectance confocal microscopy as noninvasive diagnostic methods. We report the case of a 62-year-old woman with a locally advanced basal cell carcinoma successfully treated with vismodegib in which dermoscopy and reflectance confocal microscopy showed their superiority in detecting subclinical recurrent basal cell carcinoma developed on scar tissue after complete regression of the tumor.
\end{abstract}

Keywords: Vismodegib; Reflectance confocal microscopy; Dermoscopy; Basal cell carcinoma; Nonmelanoma skin cancer

\footnotetext{
A. Villani $(\bowtie) \cdot$ G. Fabbrocini · C. Costa .

M. Scalvenzi

Dermatology Unit, Department of Clinical Medicine

and Surgery, University of Naples Federico II,

Naples, Italy

e-mail: ali.vil@hotmail.it
}

\section{Key Summary Points}

Surgical excision represents the treatment of choice in most cases of basal cell carcinoma, although new targeted therapies have been developed to treat the advanced ones.

To date, the Smoothened (Smo) inhibitors, vismodegib and sonidegib, are the two oral molecules approved for the treatment of advanced BCCs.

Previous studies demonstrated the superiority of dermoscopy and in vivo reflectance confocal microscopy (RCM) as noninvasive diagnostic techniques for the detection of residual or recurrent subclinical BCC.

Further studies on larger sample size should be performed to evaluate how clinical, dermoscopic, and RCM features modify during tumor regression and how to introduce them into clinical practice. 


\section{DIGITAL FEATURES}

This article is published with digital features, including a summary slide, to facilitate understanding of the article. To view digital features for this article go to https://doi.org/10.6084/ m9.figshare. 14381243

\section{INTRODUCTION}

Basal cell carcinoma (BCC) is the most common skin cancer, with an increasing incidence worldwide; while surgical excision represents the treatment of choice in most cases, new targeted therapies have been developed to treat the advanced ones. To date, the Smoothened (Smo) inhibitors, vismodegib and sonidegib, are the two oral molecules approved for the treatment of advanced BCCs $[1,2]$. Clinical assessment of tumor remission during and after Smo-inhibitor therapy can be challenging because treatment response changes the clinical features of the tumor, inducing the development of scar tissue that replaces tumor tissue. Moreover, clinical detection of residual or recurring subclinical BCC after Smo-inhibitor treatment could also be difficult, requiring the use of more accurate diagnostic techniques to ensure the most effective outcome. Previous studies demonstrated the superiority of dermoscopy and in vivo reflectance confocal microscopy (RCM) as noninvasive diagnostic techniques for the detection of residual BCC in patients with locally advanced (la) BCCs treated with vismodegib $[3,4]$.

\section{CASE}

Herein, we report the case of a 62-year-old woman with a laBCC, successfully treated with vismodegib in which dermoscopy and RCM showed their superiority in detecting subclinical recurrent BCC developed on scar tissue after complete regression of the tumor. The patient gave written informed consent for publication of her case details and images. The patient presented to our department with an inoperable exophytic lesion, measuring $6 \times 6 \mathrm{~cm}$ in diameter and $4 \mathrm{~cm}$ in depth, involving the left side of the upper back that was biopsied and histologically diagnosed as an infiltrative BCC, aggressive type (Fig. 1a). Beyond the esthetic disfigurement, pain was referred. Radiation therapy was not considered as an option because of cumulative dose limitations to critical structures. Given the tumor dimensions, she was placed on vismodegib treatment, an oral inhibitor of the hedgehog pathway given at the approved dosage of $150 \mathrm{mg}$ daily. After 6 months of treatment, the patient presented an excellent response with approximately $>80 \%$ tumor regression. Complete remission of the tumor was achieved and histologically confirmed after 40 weeks of vismodegib treatment (Fig. 1b). Vismodegib was discontinued, and the patient received her monthly follow-up. At 5-month follow-up, clinical examination showed the development of three small red-pink papular lesions on the left part of scar tissue (Fig. 1c); dermoscopic examination of the papules showed the presence of grey-blue globules and short-fine teleangictasias suspicious for pigmented BCC developed on the whitish background of scar tissue (Fig. 1d). Basal cell carcinoma diagnosis was also confirmed at reflectance confocal microscopy (RCM) examination [5]. The presence of tumor islands with peripheral thickened collagen bundles and dark peritumoral clefts were described, confirming the proposed diagnosis of pigmented BCC. RCM examination is shown in Fig. 1. Tumoral lesion was surgically excised and BCC histologically confirmed. The patient continues monthly follow-up visits.

\section{DISCUSSION}

Clinical assessment of complete tumor remission after vismodegib treatment can be challenging because scar tissue developed as clinical response could be mistaken as tumor, and vice versa. The superiority of dermoscopy and RCM on clinical examination as noninvasive diagnostic imaging techniques for the detection of residual or recurring subclinical BCC during or after vismodegib treatment has already been pointed out in previous studies [3]; moreover, 

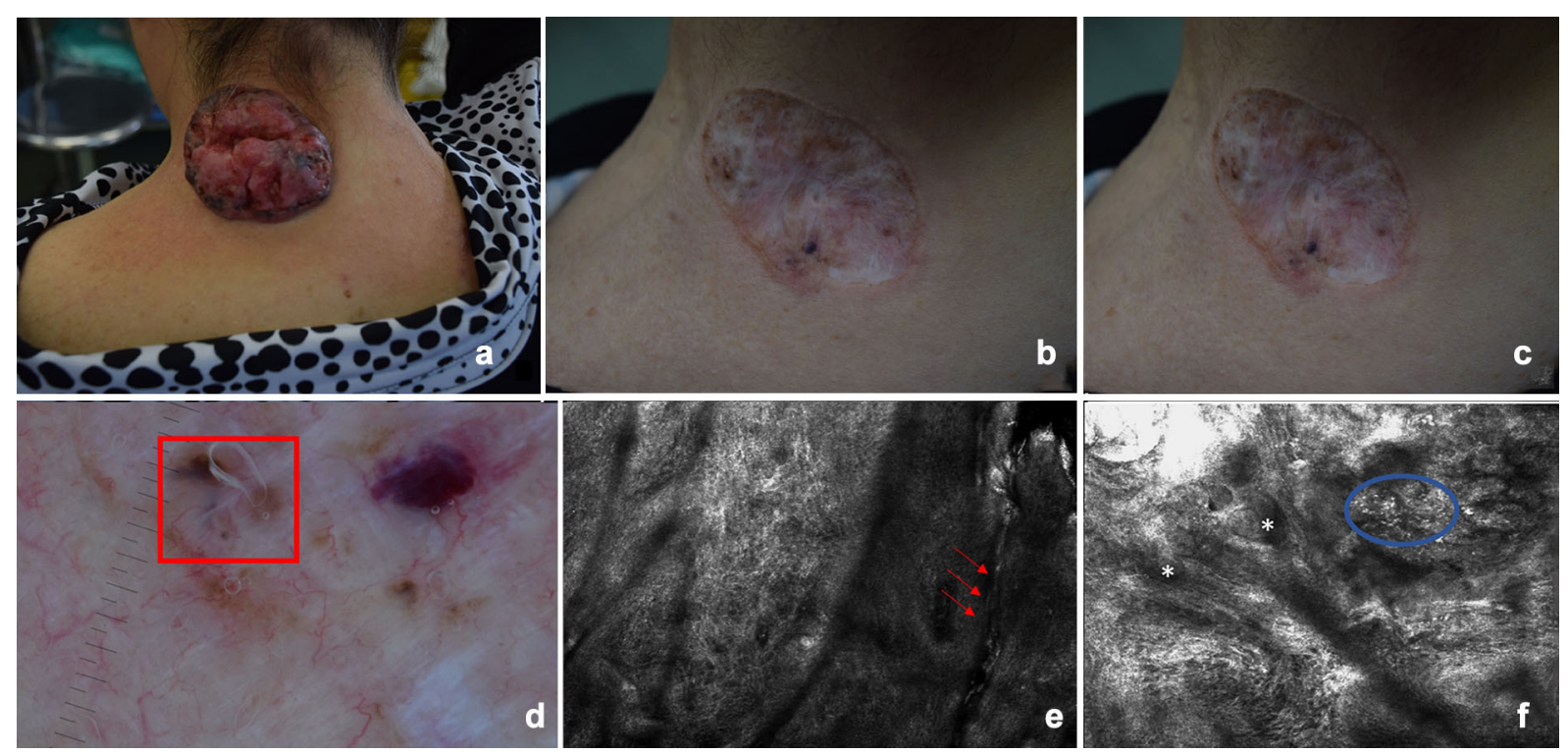

Fig. 1 a Advanced basal cell carcinoma (BCC) before vismodegib treatment. An exophytic lesion, measuring $6 \times 6 \mathrm{~cm}$ in diameter and $4 \mathrm{~cm}$ in depth and involving the left side of the upper back. (b) Complete remission of the BCC after 40-week vismodegib treatment. (c) Development of three small red-pink papular lesions on the left part of scar tissue (red square) after 5 months from vismodegib discontinuation. (d) Dermoscopic examination (polarized dermoscopy 10x) of the papules revealed presence of grey-blue globules and short-fine

clinical detection of subclinical BCC during or after vismodegib treatment could be difficult when BCC, approaching total regression, becomes too small. Methodical use of RCM could be a strategy to avoid useless and repeated biopsies, being a fast and noninvasive diagnostic method. This case confirms previous observations, also underlying the importance of monthly follow-up visits for patients treated with hedgehog inhibitors to assess response, manage possible adverse events, and detect the possible recurrence of the tumor after treatment discontinuation $[6,7]$.

\section{CONCLUSION}

This report underlines how RCM could be of great help for follow-up of BCC during and after vismodegib treatment to avoid the risk of stopping treatment before complete remission with teleangictasias suspicious for subclinical pigmented BCC. (e) Reflectance confocal microscopy (RCM) of the papules revealed the presence of sharply demarcated cords connected to the epidermis outlined by dark peritumoral clefting (red arrows). (f) Tumor islands (white asterisks) and clumps of melanophages (blue circle) typical of pigmented BCCs

subsequent recurrence. Further studies with larger sample size should be performed to evaluate how clinical, dermoscopic, and RCM features modify during tumor regression and study how these noninvasive techniques should be integrated into clinical practice to detect subclinical BCCs.

\section{ACKNOWLEDGMENTS}

We thank the participant of the study

Funding. No funding or sponsorship was received for the publication of this study.

Disclosures. Alessia Villani, Gabriella Fabbrocini, Claudia Costa, and Massimiliano Scalvenzi have nothing to disclose. 
Compliance with Ethics Guidelines. The patient gave written informed consent for publication of her case details and images.

Authorship. All named authors meet the International Committee of Medical Journal Editors (ICMJE) criteria for authorship for this article, take responsibility for the integrity of the work as a whole, and have given their approval for this version to be published.

Author contributions. All authors take responsibility for the integrity of the work as a whole, and have given final approval to the version to be published.

Data availability. The data that support the findings of this study are available on request from the corresponding author. The data are not publicly available due to privacy or ethical restrictions.

Open Access. This article is licensed under a Creative Commons Attribution-NonCommercial 4.0 International License, which permits any non-commercial use, sharing, adaptation, distribution and reproduction in any medium or format, as long as you give appropriate credit to the original author(s) and the source, provide a link to the Creative Commons licence, and indicate if changes were made. The images or other third party material in this article are included in the article's Creative Commons licence, unless indicated otherwise in a credit line to the material. If material is not included in the article's Creative Commons licence and your intended use is not permitted by statutory regulation or exceeds the permitted use, you will need to obtain permission directly from the copyright holder. To view a copy of this licence, visit http:// creativecommons.org/licenses/by-nc/4.0/.

\section{REFERENCES}

1. Mohan SV, Chang ALS. Advanced basal cell carcinoma: epidemiology and therapeutic innovations. Curr Dermatol Rep. 2014;3(1):40-5.

2. Villani A, Fabbrocini G, Costa C, Scalvenzi M. Sonidegib: safety and efficacy in treatment of advanced basal cell carcinoma. DermatolTher (Heidelb). 2020;10(3):401-12. https://doi.org/10.1007/ s13555-020-00378-8 (Epub 2020 Apr 15).

3. Couzan C, Cinotti E, Labeille B, Vercherin P, Rubegni P, Cambazard F, Perrot JL. Reflectance confocal microscopy identification of subclinical basal cell carcinomas during and after vismodegib treatment. J Eur Acad Dermatol Venereol. 2018;32(5):763-7. https://doi.org/10.1111/jdv.14650 (Epub 2017 Nov 9).

4. Alarcon I, Pasquali P, Malvehy J, Puig S. Tumor regrowth and development of keratinocytic neoplasms in patients under smoothened inhibition: in vivo assessment with reflectance confocal microscopy. Skin Res Technol. 2017;23(3):283-8. https:// doi.org/10.1111/srt.12332 (Epub 2016 Oct 27).

5. Pérez-Anker J, Ribero S, Yélamos O, García-Herrera A, Alos L, Alejo B, Combalia M, Moreno-Ramírez D, Malvehy J, Puig S. Basal cell carcinoma characterization using fusion ex vivo confocal microscopy: a promising change in conventional skin histopathology. Br J Dermatol. 2020;182(2):468-76. https://doi. org/10.1111/bjd.18239.

6. Villani A, Megna M, Fabbrocini G, Cappello M, Luciano MA, Costa C, Scalvenzi M. Long-term efficacy of vismodegib after its withdrawal and patients' health-related quality of life using the dermatology life quality index (DLQI). DermatolTher (Heidelb). 2019;9(4):719-24. https://doi.org/10.1007/s13555019-00323-4 (Epub 2019 Sep 10).

7. Tognetti L, Cinotti E, Fiorani D, et al. Long-term therapy of multiple basal cell carcinomas: clinicodermoscopic score for monitoring of intermittent vismodegib treatment. DermatolTher. 2019;32(6): 13097. https://doi.org/10.1111/dth.13097 (Epub 2019 Oct 17). 